\title{
Kinetics and Mechanism of Oxidation of D-Galactose by Chromium(VI) in Presence of 2,2 -Bipyridine Catalyst in Aqueous Micellar Media
}

\author{
Ruhidas Bayen and Asim K. Das ${ }^{*}$
}

\author{
Department of Chemistry, Visva-Bharati University, Santiniketan 731235, India
}

\begin{abstract}
In aqueous $\mathrm{H}_{2} \mathrm{SO}_{4}$ media, the chromic acid oxidation of D-galactose in the presence and absence of 2,2 bipyridine (bpy) has been carried out under the conditions, $[\mathrm{D} \text {-galactose }]_{\mathrm{T}}>[\mathrm{Cr}(\mathrm{VI})]_{\mathrm{T}}$ at different temperatures. The monomeric species of $\mathrm{Cr}(\mathrm{VI})$ has been found to be kinetically active in the absence of bpy whereas in the bpy-catalysed path, the $\mathrm{Cr}(\mathrm{VI})$-bpy complex has been suggested as the active oxidant. In the bpy-catalysed path, $\mathrm{Cr}(\mathrm{VI})$-bpy complex receives a nucleophilic attack by the substrate to form a ternary complex, which subsequently experiences a redox decomposition (through 2e transfer) at the rate-determining step leading to the product lactone and $\mathrm{Cr}(\mathrm{IV})$-bpy complex. Then the Cr(IV)-bpy complex participates in faster steps in further oxidation of D- galactose and ultimately it is converted into $\mathrm{Cr}(\mathrm{III})$-bpy complex. In the uncatalysed path, $\mathrm{Cr}(\mathrm{VI})$-substrate ester experiences acid catalysed redox decomposition (2e-transfer) at the rate determining step. The uncatalysed path shows second order dependence on $\left[\mathrm{H}^{+}\right]$while the bpycatalysed path shows a first order dependence on $\left[\mathrm{H}^{+}\right]$. Both the uncatalysed path and bpy-catalysed path show the first order dependence on both $[\mathrm{D} \text {-galactose }]_{\mathrm{T}}$ and $[\mathrm{Cr}(\mathrm{VI})]_{\mathrm{T}}$. The bpy-catalysed path is first order in $[\mathrm{bpy}]_{\mathrm{T}}$. These observations remain unaltered in the presence of externally added surfactants. Effect of the surfactants like $N$-cetylpyridinium chloride (CPC, a cationic surfactant) and sodium dodecyl sulfate (SDS, an anionic surfactant), on both the uncatalysed and bpycatalysed paths has been studied. CPC inhibits both the uncatalysed and bpy-catalysed path, while SDS accelerates the reactions. In the catalysed path, cationic $\mathrm{Cr}(\mathrm{VI})$-bpy complex is the reactive species which is attracted by the anionic micellar head groups of SDS but repelled by the cationic micellar head groups of CPC. The neutral substrate is accumulated in the Stern layer of both types of micelles. Thus the observed micellar effects have been explained by considering the hydrophobic and electrostatic interactions between the reactants and surfactants in terms of the proposed mechanism.
\end{abstract}

Keywords: Kinetics, 2,2 -bipyridine, D-galactose, chromium(VI), surfactants.

\section{INTRODUCTION}

To understand the mechanistic aspects of reduction of $\mathrm{Cr}(\mathrm{VI})$ to $\mathrm{Cr}(\mathrm{III})$, several kinetic studies of chromic acid oxidation of different types of organic substrates have been carried out by different workers [1-3]. Kinetic studies of oxidation of different types of organic substrate by halochromate have also been investigated by different workers $[4,5]$ to explore the effect of the substituent on the redox activity of $\mathrm{Cr}(\mathrm{VI})$. In this regard, micellar effect as a powerful probe [6] has been utilised by different workers to explore the redox activity of chromium(VI) [6-9]. Among the different types of chelating agents [10-15] to catalyse the $\mathrm{Cr}(\mathrm{VI})$ oxidation of different types of organic substrates, 2,2'-bpyridyl (bpy) is quite important [16-18]. Some of the chelating agents as catalysts like oxalic acid, $\alpha$ - hydroxy acids experience cooxidation [19]. But bpy is never co-oxidised along with the substrate. In this regard, it acts always as an oxidation catalyst. During the reaction, bpy is gradually lost due to the formation of inert $\mathrm{Cr}$ (III)-bpy complex. Because of this fate bpy, it cannot be defined as a true catalyst from its definition, but loosely very often it is described as an oxidation catalyst. The present paper deals with the micellar effects on $\mathrm{Cr}(\mathrm{VI})$ oxidation D-galactose in the presence of

*Address correspondence to this author at the Department of Chemistry, Visva-Bharati University, Santiniketan 731235, India;

Tel: +91 9832185863; E-mail: ak_das3@yahoo.com bpy. The micellar effects have been studied to substantiate the proposed reaction mechanisms.

\section{EXPERIMENTAL}

\subsection{Materials and Reagents}

2,2'-Bipyridine (A.R. Qualigens, India), D-galactose (A.R. SRL, India), $\mathrm{K}_{2} \mathrm{Cr}_{2} \mathrm{O}_{7}$ (A.R. BDH), sodium dodecyl sulphate (SDS) (A.R. SRL, India), N-cetyl pyridinium chloride (CPC) (A.R.SRL, India), $\mathrm{H}_{2} \mathrm{SO}_{4}$ (E. Merck), $\mathrm{HClO}_{4}$ (E. Merck) and all other chemicals used are of highest purity available commercially. Solutions were prepared in doubly distilled water.

\subsection{Procedure and Kinetic Measurements}

Solutions of the oxidant and reaction mixtures containing the known quantities of the substrate (S) (i.e. D-galactose), catalyst (bpy), under the kinetic conditions, [D-galactose $]_{\mathrm{T}}$ $\gg[\mathrm{Cr}(\mathrm{VI})]_{\mathrm{T}}$ and $[\mathrm{bpy}]_{\mathrm{T}} \gg[\mathrm{Cr}(\mathrm{VI})]_{\mathrm{T}}$, acid and other necessary chemicals were separately thermostated $\left( \pm 0.1^{\circ} \mathrm{C}\right)$. The reaction was initiated by mixing the requisite amounts of the oxidant with the reaction mixture. Progress of the reaction was monitored by following the rate of disappearance of $\mathrm{Cr}(\mathrm{VI})$ by titrimetric quenching technique [20] as discussed earlier.

The pseudo first order constants $\left(k_{\mathrm{obs}}\right)$ were calculated as usual. Under the experimental conditions, possibility of decomposition of the surfactants by $\mathrm{Cr}(\mathrm{VI})$ has been 
investigated and the rate of decomposition has been found negligible.

\subsection{Product Analysis and Stoichiometry}

Under the kinetic conditions (i.e. $[\mathrm{D} \text {-galactose }]_{\mathrm{T}}>>$ $\left.[\mathrm{Cr}(\mathrm{VI})]_{\mathrm{T}}\right)$, qualitative identification of the reaction product was carried out by paper-chromatography [21-23]. Paper chromatograph was effected by using butan-1-ol-acetic acidwater (4:1:5) mixture as an elutent. Paper chromatography was visualised by using two developing reagents: a three stage dip of silver nitrate, sodium hydroxide and sodium thiosulfate [24] and $\beta$-napthol-sulfanilamide. These are specific for aldonic acids. D-galactonic acid was identified by comparison with the chromatogram of authentic sample obtained as the oxidation product of $\mathrm{D}$-galactose by bromine water [25]

The final fate of the $\mathrm{Cr}(\mathrm{III})$-species has been confirmed by spectroscopically. The UV-visible spectra (Figs. 1 and 2) were recorded by using the spectrophotometer (UV-VIS-NIR Scanning Spectrophotometer, UV-3101PC, Shimadzu). The reaction solution was scanned (in the range 350-700 $\mathrm{nm}$ ) at regular intervals to follow the gradual development of the reaction intermediate (if any) and product spectrophotometrically. The scanned spectrum (Fig. 1) indicates the gradual disappearance of $\mathrm{Cr}(\mathrm{VI})$-species and appearance of $\mathrm{Cr}$ (III)-species with the isosbestic point at $\lambda=$ $525 \mathrm{~nm}$. Observation of this single isosbestic point indicates the very low concentration of the probable intermediates [26] like $\mathrm{Cr}(\mathrm{V})$ and $\mathrm{Cr}(\mathrm{IV})$ under the present experimental conditions. In other words, it indicates the gradual decrease of $\mathrm{Cr}(\mathrm{VI})$ with the concomitant increase of $\mathrm{Cr}(\mathrm{III})$. The characteristic part of electronic absorption spectra of $\mathrm{Cr}$ (III)species lies in the range $370-700 \mathrm{~nm}$. The colour of the final solution of bpy-catalysed reaction in aqueous $\mathrm{H}_{2} \mathrm{SO}_{4}$ media is pale violet $\left[\lambda_{\max }=542 \mathrm{~nm}\right.$ for $\left.{ }^{4} \mathrm{~A}_{2 \mathrm{~g}} \rightarrow{ }^{4} \mathrm{~T}_{2 \mathrm{~g}}\right]$ while the colour of the final solution for the uncatalysed reaction (i.e. in absence of bpy) under the identical condition is pale blue $\left[\lambda_{\max }=580 \mathrm{~nm}\right.$ for ${ }^{4} \mathrm{~A}_{2 \mathrm{~g}} \rightarrow{ }^{4} \mathrm{~T}_{2 \mathrm{~g}}$; and $415 \mathrm{~nm}$ for ${ }^{4} \mathrm{~A}_{2 \mathrm{~g}} \rightarrow$ $\left.{ }^{4} \mathrm{~T}_{1 \mathrm{~g}}(\mathrm{~F})\right]$. The spectra of the final solution of the uncatalysed reaction and pure chromic sulfate solution in aqueous sulfuric acid media are identical. It indicates that the final $\mathrm{Cr}$ (III)-species is simply chromic sulfate for the uncatalysed reaction while for the bpy-catalysed reaction, the final $\mathrm{Cr}$ (III)-species is a Cr(III)-bpy complex. The similar results have been noted by the earlier workers $[18,27]$. It is quite interesting to note that for the final solution of the bpycatalysed reaction, there is a blue shift ( $c f$. Fig. 2) for the peak due to the transition ${ }^{4} \mathrm{~A}_{2 \mathrm{~g}} \rightarrow{ }^{4} \mathrm{~T}_{2 \mathrm{~g}}$. This blue shift is due to the presence of the strong field ligand like bpy. For the said $\mathrm{Cr}$ (III)-bpy complex the peak due to the transition ${ }^{4} \mathrm{~A}_{2 \mathrm{~g}}$ $\rightarrow{ }^{4} \mathrm{~T}_{1 \mathrm{~g}}(\mathrm{~F})$ merges with the charge transfer band ( $c f$. Fig. 2). The appearance of the charge transfer band at much lower energy for the proposed $\mathrm{Cr}$ (III)-bpy complex is quite reasonable because of the favoured metal to ligand charge transfer. In fact, the vacant $\Pi^{*}$ of bpy favours the metal to ligand charge transfer. The existence of the charge transfer band (metal to ligand) at this lower energy for the bpycatalysed reaction indirectly supports the proposition of the $\mathrm{Cr}(\mathrm{III})$-bpy complex in the final solution.

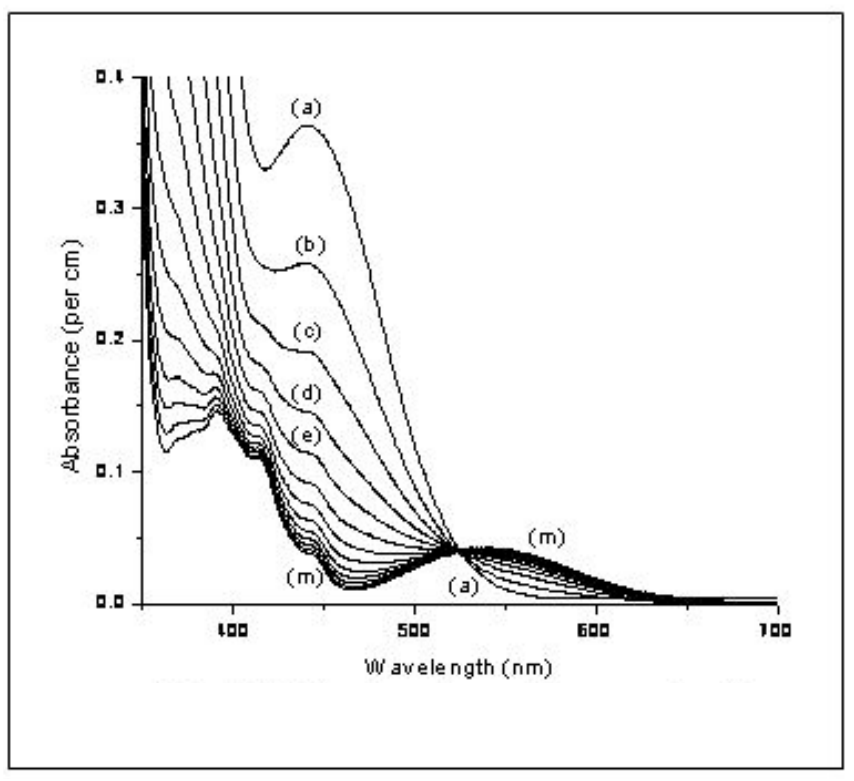

Fig. (1). Scanned absorption spectra of the reaction mixture at regular time intervals (4 minute e.g. a: at the beginning of reaction; b: after 4 min.; c: after $8 \mathrm{~min}$.; and so on upto $\mathbf{m}$ : after $48 \mathrm{~min}$.). Concentrations at the beginning of the reaction, $[\mathrm{Cr}(\mathrm{VI})]_{\mathrm{T}}=2.0 \times 10^{-}$ ${ }^{3} \mathrm{~mol} \mathrm{dm}^{-3},[\mathrm{bpy}]_{\mathrm{T}}=7.0 \times 10^{-3} \mathrm{~mol} \mathrm{dm}^{-3},\left[\mathrm{H}_{2} \mathrm{SO}_{4}\right]=0.5 \mathrm{~mol} \mathrm{dm}^{-3}$, $[\text { D-galactose }]_{\mathrm{T}}=25 \times 10^{-3} \mathrm{~mol} \mathrm{dm}^{-3}, \mathrm{~T}=30^{\circ} \mathrm{C}$.

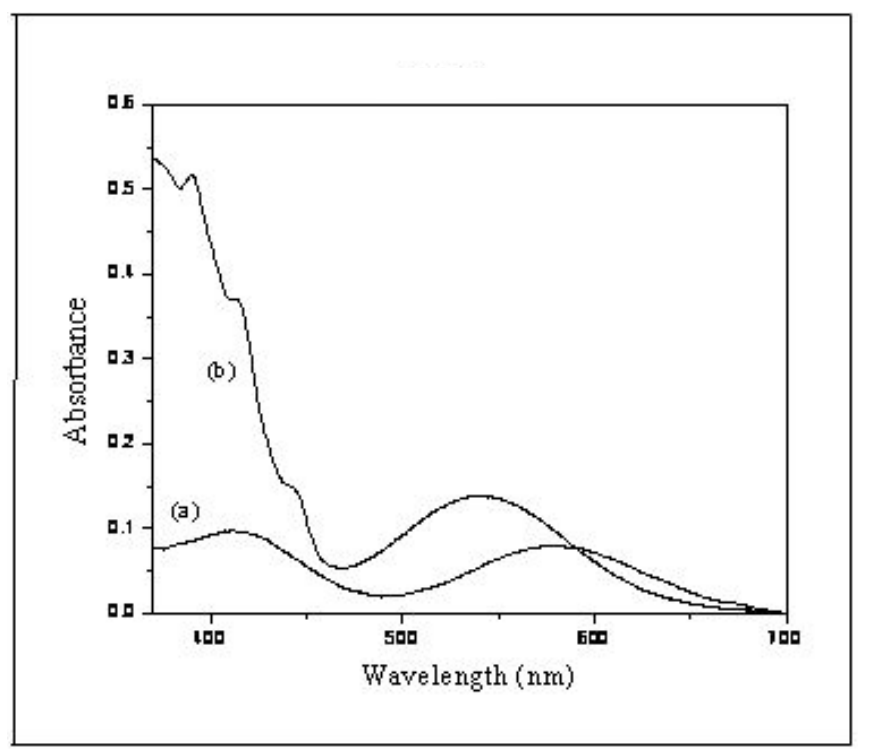

Fig. (2). (a) Absorption spectra (absorbance per $\mathrm{cm}$ ) of the reaction mixture (after completion of reaction): $[\mathrm{Cr}(\mathrm{VI})]_{\mathrm{T}}=4.85 \times 10^{-3} \mathrm{~mol} \mathrm{dm}^{-}$ ${ }^{3}$, $[\text { D-galactose }]_{\mathrm{T}}=80 \times 10^{-3} \mathrm{~mol} \mathrm{dm}^{-3},[\mathrm{bpy}]_{\mathrm{T}}=0 \mathrm{~mol} \mathrm{dm}^{-3}$ (i.e. uncatalysed path), $\left[\mathrm{H}_{2} \mathrm{SO}_{4}\right]=0.5 \mathrm{~mol} \mathrm{dm}^{-3}$. (The spectrum of the chromic sulfate is identical with this under the experimental condition). (b) Absorption spectra (absorbance per $\mathrm{cm}$ ) of the reaction mixture (after completion of reaction): $[\mathrm{Cr}(\mathrm{VI})]_{\mathrm{T}}=4.85 \times 10^{-3}$ mol dm ${ }^{-3},[\text { D-galactose }]_{\mathrm{T}}=80 \times 10^{-3} \mathrm{~mol} \mathrm{dm}^{-3},[\mathrm{bpy}]_{\mathrm{T}}=14 \times 10^{-3} \mathrm{~mol}$ $\mathrm{dm}^{-3},\left[\mathrm{H}_{2} \mathrm{SO}_{4}\right]=0.5 \mathrm{~mol} \mathrm{dm}^{-3}$.

\section{RESULTS AND DISCUSSION}

\subsection{Dependence on $[\mathrm{Cr}(\mathrm{VI})]_{\mathrm{T}}$}

In the presence and absence of bpy, under the experimental conditions, $[\mathrm{S}]_{\mathrm{T}} \gg[\mathrm{bpy}]_{\mathrm{T}}>[\mathrm{Cr}(\mathrm{VI})]_{\mathrm{T}}$, the rate of disappearance of $\mathrm{Cr}(\mathrm{VI})$ shows a first order 
dependence on $[\mathrm{Cr}(\mathrm{VI})]$. This dependence is also maintained in the presence of surfactants CPC and SDS. $[\mathrm{S}]_{\mathrm{T}}$ denotes the total substrate i.e. D-galactose concentration. The pseudo first order rate constants $\left(k_{\mathrm{obs}}\right)$ have been evaluated from the linear plot of $\log [\mathrm{Cr}(\mathrm{VI})]_{\mathrm{T}} v s$ time $(\mathrm{t})$ as usual.

\subsection{Dependence on $[\mathrm{bpy}]_{\mathrm{T}}$}

The effect of [bpy $]_{\mathrm{T}}$ on $k_{\mathrm{obs}}$ has been followed in aqueous $\mathrm{H}_{2} \mathrm{SO}_{4}$ media. The plots of $k_{\mathrm{obs}} v s[\mathrm{bpy}]_{\mathrm{T}}$ are linear $(\mathrm{r}>0.99)$ with positive intercepts measuring the contribution of the relatively slower uncatalysed path. The pseudo first order rate constants, $k_{\mathrm{obs}(\mathrm{u})}$ directly measured in absence of catalyst, bpy nicely agree with those obtained from the intercepts of the plots of $k_{\mathrm{obs}(\mathrm{T})} v s[\mathrm{bpy}]_{\mathrm{T}}$. The observation is formulated as follows:

$k_{\mathrm{obs}(\mathrm{T})}=k_{\mathrm{obs}(\mathrm{u})}+k_{\mathrm{obs}(\mathrm{c})}=k_{\mathrm{obs}(\mathrm{u})}+k_{\mathrm{cat}}[\mathrm{bpy}]_{\mathrm{T}}$

The values of $k_{\text {cat }}$ with the activation parameters are given in Table 1. During the progress of reaction, bpy is lost due to the formation of inert $\mathrm{Cr}$ (III)-bpy complex. Under the conditions, $[\mathrm{bpy}]_{\mathrm{T}}>>[\mathrm{Cr}(\mathrm{VI})]_{\mathrm{T}}$, during the progress of the reaction, $[\mathrm{bpy}]_{\mathrm{T}}$ remains more or less constant.

\subsection{Dependence on $[S]_{T}$}

From the plot of $k_{\mathrm{obs}} v S[\mathrm{~S}]_{\mathrm{T}}$ it is established that the catalysed paths show the first order dependence on $[\mathrm{S}]_{\mathrm{T}}$ where $\mathrm{S}$ denotes $\mathrm{D}$-galactose,

$k_{\mathrm{obs}(\mathrm{c})}=k_{\mathrm{obs}(\mathrm{T})}-k_{\mathrm{obs}(\mathrm{u})}=k_{\mathrm{s}(c)}[\mathrm{S}]_{\mathrm{T}}$

$k_{\mathrm{obs}(\mathrm{u})}=k_{\mathrm{s}(\mathrm{u})}[\mathrm{S}]_{\mathrm{T}}$

Under the experimental conditions ( $c f$. Table 1), in uncatalysed path (in presence of CPC) $k_{\mathrm{s}(\mathrm{u})(\mathrm{cpc})}$ is almost equal to zero. It leads to: $k_{\mathrm{s}(\mathrm{c})(\mathrm{cpc})}=k_{s(\mathrm{~T})(\mathrm{cpc})}-k_{s(\mathrm{u})(\mathrm{cpc})} \approx k_{\mathrm{s}(\mathrm{T})(\mathrm{cpc})}$.

\subsection{Dependence on $\left[\mathrm{H}^{+}\right]$}

From the experimental fit, the acid dependence patterns for the uncatalysed and catalysed paths appear to be different. The observations are

$k_{\mathrm{obs}(\mathrm{u})}=k_{\mathrm{H}(\mathrm{u})}\left[\mathrm{H}^{+}\right]^{2}$

$k_{\mathrm{obs}(\mathrm{c})}=k_{\mathrm{H}(\mathrm{c})}\left[\mathrm{H}^{+}\right]$

\section{TEST FOR ACRYLONITRILE POLYMERISATION}

Under the experimental conditions, polymerization of acrylonitrile was observed under a nitrogen atmosphere.

\section{MECHANISM OF THE REACTION}

Mechanism of the reaction can be divided in two sections: (i) uncatalysed path (Scheme 1a \& 1b) and (ii) catalysed path (Scheme 2).

\subsection{Uncatalysed Path}

The reactions were carried out in aqueous sulfuric acid media $\left(0.2-1.25 \mathrm{~mol} \mathrm{dm}^{-3}\right)$. In this condition, $\mathrm{Cr}(\mathrm{VI})$ mainly exist as $\mathrm{H}_{2} \mathrm{CrO}_{4}$ and a small amount as $(\mathrm{HO}) \mathrm{CrO}_{2}\left(\mathrm{OS}_{3} \mathrm{O}_{3} \mathrm{H}\right)$. (i.e. chromyl sulfate) [28]. However, this distribution of $\mathrm{Cr}(\mathrm{VI})$ species does not complicate our studies because effect of different substances on the rate process was carried out at a fixed $\left[\mathrm{H}_{2} \mathrm{SO}_{4}\right]$. Effect of sulfuric acid was not studied to avoid the complication. To understand the effect of $\mathrm{H}^{+}$, $\mathrm{HClO}_{4}$ was used. It is worth mentioning the $\mathrm{HClO}_{4}$ could not be used throughout the experiment because of the solubility problem of surfactants. Galactose exist predominantly as hemiacetal cyclic forms (i.e. pyranoid) of $\alpha$ (OH-1, axial) and $\beta$ (OH-1, equatorial) anomers [29-31] in presence of acid. The concentration of the open chain aldehyde form [32], which is the intermediate in the dynamic equilibrium between the anomers is very small. The rate of mutarotation (i.e. $\alpha$-D-galactose $\longrightarrow \beta$-D-galactose) is known to be acid catalysed [33] and under the experimental condition, the mutarotation equilibrium is immediately attained [33]. Thus the rate of oxidation of galactose is the summation of rates contributed by each of the $\alpha$ - and $\beta$-anomers in addition to the possible contribution from the open chain aldehyde form [21]. The cyclic hemiacetal forms are expected to be better reactive species where the hydroxy groups are better exposed to interact with the $\mathrm{Cr}(\mathrm{VI})$ species [22]. In fact, esterification of the $-\mathrm{OH}$ group of the substrate with the chromic acid is the first step of $\mathrm{Cr}(\mathrm{VI})$ oxidation of the title substrate. Among the $\alpha$ - and $\beta$-anomers, the $\beta$-form bearing the $-\mathrm{OH}$ group at $\mathrm{Cl}$ at the equatorial position is more suitably exposed [34] to be attacked by chromic acid. Thus

Table 1. Kinetic Parameters and Some Representative Rate Constants for the Cr(VI) Oxidation of D-Galactose in the Presence of 2,2'-Bipyridine in Aqueous $\mathrm{H}_{2} \mathrm{SO}_{4}$ Media

\begin{tabular}{|c|c|c|c|c|c|c|c|c|c|}
\hline Temp $\left({ }^{\circ} \mathrm{C}\right)$ & $\begin{array}{c}10^{4} k_{\text {obs }(u)(w)} / \\
\left(s^{-1}\right)^{2}\end{array}$ & $\begin{array}{c}10^{2} k_{\text {cat }(w)} / \\
\left(\mathrm{dm}^{3} \mathrm{~mol}^{-1} \mathrm{~s}^{-1}\right)^{\mathrm{a}}\end{array}$ & $\begin{array}{c}10^{2} k_{\text {cat(cpc) }} / \\
\left(\mathrm{dm}^{3} \mathrm{~mol}^{-1} \mathrm{~s}^{-1}\right)^{\mathrm{a}}\end{array}$ & $\begin{array}{c}10^{2} k_{\text {catt(sds) }} / \\
\left(\mathrm{dm}^{3} \mathrm{~mol}^{-1} \mathrm{~s}^{-1}\right)^{\mathrm{a}}\end{array}$ & $\boldsymbol{k}_{\text {eff(w) }}^{\mathrm{a}}$ & $\begin{array}{c}10^{4} k_{\mathrm{H}(\mathrm{c})(\mathrm{w} w} / \\
\left(\mathrm{dm}^{3} \mathrm{~mol}^{-1} \mathrm{~s}^{-1}\right)^{\mathrm{b}}\end{array}$ & $\begin{array}{c}10^{2} k_{\mathrm{s}(\mathrm{c})(\mathrm{wv}} / \\
\left(\mathrm{dm}^{3} \mathrm{~mol}^{-1} \mathrm{~s}^{-1}\right)^{\mathrm{c}}\end{array}$ & $\begin{array}{c}10^{2} k_{\mathrm{s}(\mathrm{c})(\mathrm{sds})} / \\
\left(\mathrm{dm}^{3} \mathrm{~mol}^{-1} \mathrm{~s}^{-1}\right)^{\mathrm{c}}\end{array}$ & $\begin{array}{c}10^{2} k_{\text {s(c)(cpc }} / \\
\left(\mathrm{dm}^{3} \mathrm{~mol}^{-1} \mathrm{~s}^{-1}\right)^{\mathrm{c}}\end{array}$ \\
\hline & & & & & & & $6.50 \pm 0.4$ & $10.70 \pm 0.5$ & $2.4 \pm 0.1$ \\
\hline $35^{\circ} \mathrm{C}$ & 0.4 & $4.7 \pm 0.2$ & $2.3 \pm 0.1$ & $6.1 \pm 0.3$ & 5.57 & $13.75 \pm 0.2$ & & & \\
\hline $45^{\circ} \mathrm{C}$ & 0.8 & $6.1 \pm 0.3$ & & & 3.64 & & & & \\
\hline $55^{\circ} \mathrm{C}$ & 0.9 & $8.6 \pm 0.4$ & & & 3.45 & & & & \\
\hline \multicolumn{2}{|c|}{$\Delta \mathrm{H}^{\neq}\left(\mathrm{kJ} \mathrm{mol}^{-1}\right)$} & $32 \pm 0.2$ & & & & & & & \\
\hline \multicolumn{2}{|c|}{$\Delta \mathrm{S}^{\neq}\left(\mathrm{JK}^{-1} \mathrm{~mol}^{-1}\right)$} & $-168 \pm 10$ & & & & & & & \\
\hline
\end{tabular}

Subscript (u) for uncatalysed path; (c) for bpy catalysed path; (w) for the value in the absence of surfactant; (CPC) or (SDS) for the value in presence of the respective surfactant. ${ }^{\mathrm{a}}[\mathrm{Cr}(\mathrm{VI})]_{\mathrm{T}}=5 \times 10^{-4} \mathrm{~mol} \mathrm{dm}^{-3},[\mathrm{~S}]_{\mathrm{T}}=6.0 \times 10^{-3} \mathrm{~mol} \mathrm{dm}^{-3},\left[\mathrm{H}_{2} \mathrm{SO}_{4}\right]=0.5 \mathrm{~mol} \mathrm{dm}^{-3},[\mathrm{bpy}]_{\mathrm{T}}=\left(0-1.6 \times 10^{-2}\right) \mathrm{mol} \mathrm{dm}^{-3},[\mathrm{CPC}]_{\mathrm{T}}=6 \times 10^{-3} \mathrm{~mol} \mathrm{dm}^{-3},[\mathrm{SDS}]_{\mathrm{T}}=8 \times 10^{-3} \mathrm{~mol} \mathrm{dm}^{-3}$ and $k_{\mathrm{eff}(\mathrm{w})}=$ $\left[k_{\mathrm{obs}(\mathrm{T})}-k_{\mathrm{obs}(\mathrm{u})}\right] / k_{\mathrm{obs}(\mathrm{u})}$ and $k_{\mathrm{eff}(\mathrm{w})}$ calculated at $[\mathrm{bpy}]_{\mathrm{T}}=1.0 \times 10^{-3} \mathrm{~mol} \mathrm{dm}^{-3}$.

${ }^{\mathrm{b}}[\mathrm{Cr}(\mathrm{VI})]_{\mathrm{T}}=5.0 \times 10^{-4} \mathrm{~mol} \mathrm{dm}^{-3},[\mathrm{~S}]_{\mathrm{T}}=15 \times 10^{-3} \mathrm{~mol} \mathrm{dm}^{-3},[\mathrm{bpy}]_{\mathrm{T}}=0.4 \times 10^{-2} \mathrm{~mol} \mathrm{dm}^{-3},\left[\mathrm{H}^{+}\right]_{\mathrm{T}}=(0.2-1.25) \mathrm{mol} \mathrm{dm}^{-3},\left[\mathrm{HClO}_{4}\right]_{\mathrm{T}}+\left[\mathrm{NaClO}_{4}\right]_{\mathrm{T}}=1.5 \mathrm{~mol} \mathrm{dm}^{-3}$

${ }^{\mathrm{c}}[\mathrm{Cr}(\mathrm{VI})]_{\mathrm{T}}=5 \times 10^{-4} \mathrm{~mol} \mathrm{dm}^{-3},[\mathrm{~S}]_{\mathrm{T}}=\left(1-10 \times 10^{-3}\right) \mathrm{mol} \mathrm{dm}^{-3},[\mathrm{bpy}]_{\mathrm{T}}=10 \times 10^{-3} \mathrm{~mol} \mathrm{dm}^{-3},\left[\mathrm{H}_{2} \mathrm{SO}_{4}\right]=0.5 \mathrm{~mol} \mathrm{dm}^{-3},[\mathrm{CPC}]_{\mathrm{T}}=6 \times 10^{-3} \mathrm{~mol} \mathrm{dm}^{-3},[\mathrm{SDS}]_{\mathrm{T}}=8 \times 10^{-3} \mathrm{~mol} \mathrm{dm}^{-3} . \mathrm{In}^{-}$ uncatalysed path (presence of CPC) $K_{\mathrm{s}(\mathrm{u})(\mathrm{cpc})}$ is almost equal to zero. Hence $k_{\mathrm{s}(\mathrm{c})(\mathrm{cpc})}=k_{s(\mathrm{~T})(\mathrm{cpc})}-k_{s(\mathrm{u})(\mathrm{cpc})} \approx k_{\mathrm{s}(\mathrm{T})(\mathrm{cpc})}$. 


$$
\begin{aligned}
& \mathrm{Gal}-\mathrm{OH}+\mathrm{HCrO}_{4}^{-}+\mathrm{H}^{+} \stackrel{\mathrm{K}_{1}}{-} \underset{(\mathrm{A})}{\mathrm{Gal}-\mathrm{CrO}_{3} \mathrm{H}}+\mathrm{H}_{2} \mathrm{O} \\
& \mathrm{A}+\mathrm{H}^{+} \stackrel{\mathrm{K}_{2}}{=} \text { Gal-OCrO }_{3} \mathrm{H}_{2}^{+}\left(\mathrm{AH}^{+}\right) \\
& \mathrm{AH}^{+}{ }^{k_{1}}-\text { Product (P) }+\mathrm{Cr}(\mathrm{IV}) \\
& \mathrm{Cr}(\mathrm{IV}) \mathrm{Cr}(\mathrm{VI}) \text { Gal-OH }
\end{aligned}
$$

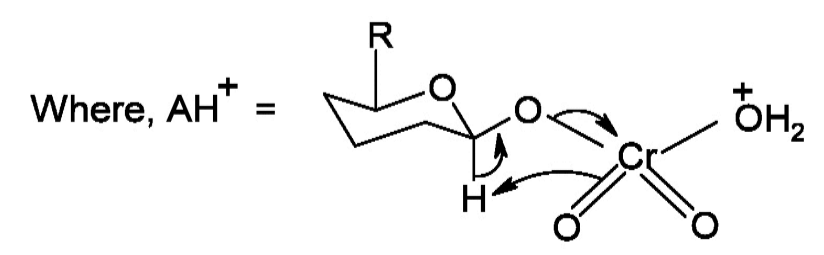

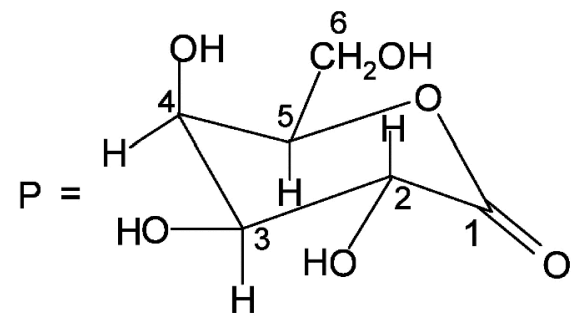

( $\delta$ lactone)

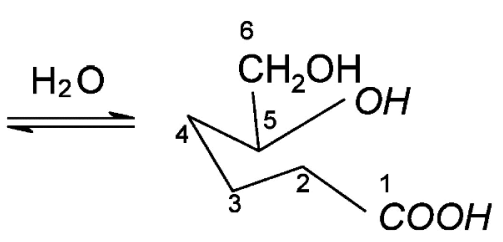

(free - galactonic)

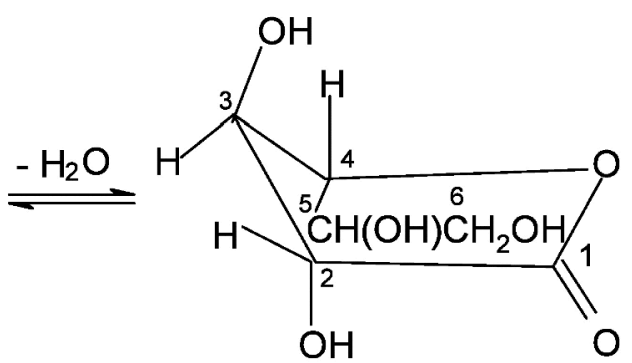

( $\gamma$ lactone )

Scheme1. Cr(VI) oxidation of D - galactose (denoted by Gal-OH) in the absence of 2,2'-bipyridine. (For the sake of simplicity, other coordinated water molecules at the Cr-centre are not shown).

galactose is mainly oxidised to the $4 \mathrm{C} 1 \beta$-pyranoid form and the initial product is the corresponding lactone. We have already established the uncatalysed [35] path (Scheme 1) for D-galactose as follows:

$k_{\mathrm{obs}(\mathrm{u})}=(2 / 3) k_{1} K_{1} K_{2}[\mathrm{~S}]_{\mathrm{T}}\left[\mathrm{H}^{+}\right]^{2}$

\subsection{Catalysed Path}

The findings for the bpy-catalysed reactions can be explained by considering the reaction mechanism outlined in Scheme 2 and it leads to the following rate law:

$k_{\mathrm{obs}(\mathrm{c})}=(2 / 3) k_{2} K_{3} K_{4}[\mathrm{~S}]_{\mathrm{T}}[\mathrm{L}]_{\mathrm{T}}\left[\mathrm{H}^{+}\right](15)$

The product, $\mathrm{Cr}(\mathrm{III})$-bpy complex has been characterized spectroscopically. $\mathrm{Cr}(\mathrm{III})\left(\mathrm{t}_{2 \mathrm{~g}}{ }^{3}\right)$ is an inert centre. Hence it is reasonable to consider that the heteroaromatic N-base (i.e. bpy) does not enter to the $\mathrm{Cr}(\mathrm{III})$-centre after its formation from the reduction of $\mathrm{Cr}(\mathrm{VI})$. This is why, it is suggested that the said heteroaromatic N-base (denoted by L) undergoes complexation with the higher oxidation states of chromium which are labile. The $\mathrm{Cr}(\mathrm{VI})$-species (i.e. chromic acid) is typically labile and undergoes complexation at the first step with the chelating agent $(\mathrm{L})$ to produce the cyclic complex $\left(\mathrm{C}_{1}\right)$ which is believed to be the kinetically active oxidant [14]. Under the experimental conditions, the first order dependence on $[\mathrm{bpy}]_{\mathrm{T}}$ is strictly maintained throughout the range of $[\mathrm{bpy}]_{\mathrm{T}}$ used. Thus it is reasonable to conclude that the equilibrium constant for the reaction leading to cyclic $\mathrm{Cr}(\mathrm{VI})$-bpy complex $\left(\mathrm{C}_{1}\right)$ is low. In the next step, the $\mathrm{Cr}(\mathrm{VI})$-bpy complex reacts with the substrate to form a ternary complex (Eqn.12) which experiences a redox decomposition through a cyclic transition state at a rate limiting step giving rise to the organic product and $\mathrm{Cr}(\mathrm{IV})$ bpy complex. The negative value of $\Delta \mathrm{S}^{\neq}$(entropy of activation, cf. Table 1) of the composite rate constant $k_{\text {cat }}$ supports the suggested cyclic transition state. The $\mathrm{Cr}(\mathrm{IV})-$ species produced at the rate limiting step participates in the faster steps to give the final product. The different possible routes are given below:

$$
\begin{aligned}
& \text { Path I: } \mathrm{Cr}(\mathrm{IV})+\mathrm{Cr}(\mathrm{VI}) \rightarrow 2 \mathrm{Cr}(\mathrm{V}) \\
& 2 \mathrm{Cr}(\mathrm{V})+2 \mathrm{~S} \rightarrow 2 \mathrm{Cr}(\mathrm{III})+\text { Products } \\
& \text { Path II: } \mathrm{Cr}(\mathrm{IV})+\mathrm{S} \rightarrow \mathrm{Cr}(\mathrm{III})+\mathrm{S}^{\cdot} \\
& \mathrm{Cr}(\mathrm{VI})+\mathrm{S}^{\cdot} \rightarrow \mathrm{Cr}(\mathrm{V})+\text { Products } \\
& \mathrm{Cr}(\mathrm{V})+\mathrm{S} \rightarrow \mathrm{Cr}(\mathrm{III})+\text { Products }
\end{aligned}
$$

Path III: $\mathrm{Cr}(\mathrm{IV})+\mathrm{S} \rightarrow$ Products $+\mathrm{Cr}(\mathrm{II})$

$$
\begin{aligned}
& \mathrm{Cr}(\mathrm{II})+\mathrm{Cr}(\mathrm{VI}) \rightarrow \mathrm{Cr}(\mathrm{III})+\mathrm{Cr}(\mathrm{V}) \\
& \mathrm{Cr}(\mathrm{V})+\mathrm{S} \rightarrow \text { Products }+\mathrm{Cr}(\mathrm{III})
\end{aligned}
$$

In the above mentioned possible paths, $\mathrm{S}$ denotes the substrate acting as a $2 \mathrm{e}$ reductant and $\mathrm{S}^{\circ}$ stands for the 
<smiles>[R16][C+](C)[C+]1=NC(c2ccccn2)=CC=C1</smiles>

(L)

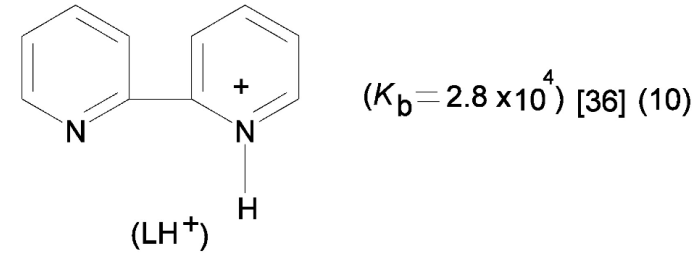

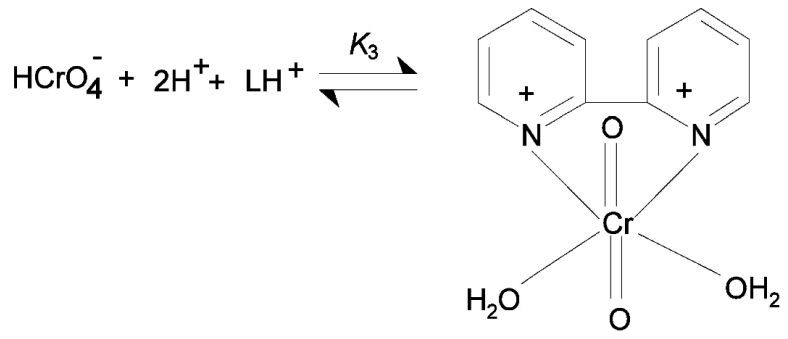

$\left(C_{1}\right)$
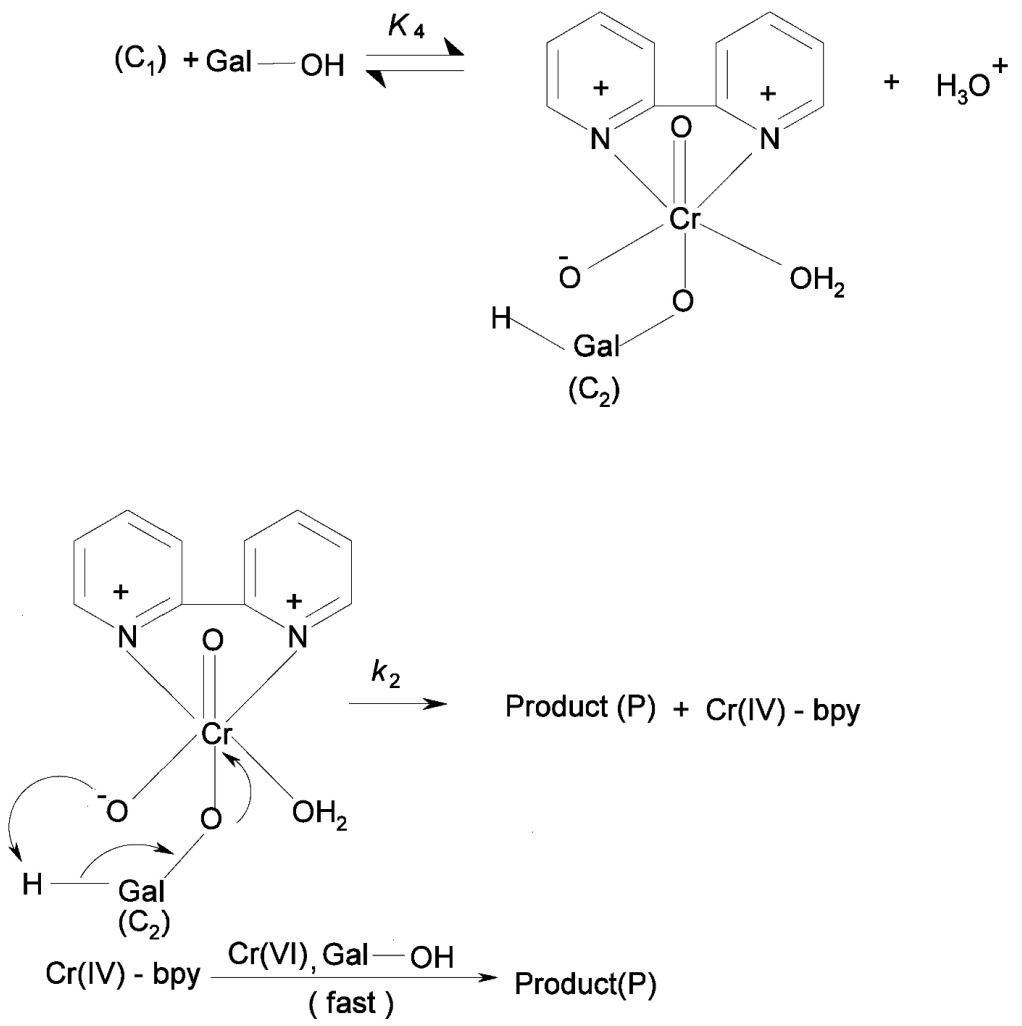

Scheme 2. $\mathrm{Cr}(\mathrm{Vl})$ oxidation of D-galactose denoted by $(\mathrm{Gal}-\mathrm{OH})$ in the presence of 2,2'-bipyridine.

partially oxidised substrate. In both the WatanabeWestheimer mechanism [37] (i.e. Path I) and the PerezBennito mechanism [1, 38, 39] (i.e. Path III), the title organic substrate acts in all steps as a $2 \mathrm{e}$ reductant, while it acts both as a $2 \mathrm{e}$ - reductant and 1e- reductant in the Rocek mechanism [40] (i.e. Path II). Previously, the Rocek mechanism [40] was accepted widely in explaining the Cr(VI) oxidation of different organic substrates and the Perez-Bennito mechanism [1, 38, 39] was discarded because of the instability of $\mathrm{Cr}$ (II). But recently, it has been proved $[1,38,39]$ that for the oxidation of different 2e-organic reductants, $\mathrm{Cr}(\mathrm{II})$ is produced from $\mathrm{Cr}(\mathrm{IV})$ through hydride transfer. Thus, the carbocationic centre generated is responsible for acrylonitrile polymerization [41]. It may be noted that in Rocek mechanism [40], the free radical $\mathrm{S}^{\bullet}$ is supposed to be responsible for acrylonitrile polymerisation.

\section{EFFECT OF CPC}

$N$-cetylpyridinium chloride (CPC), a representative cationic surfactant, has been found to show the rate retarding effect in the presence of bpy. The $k_{\mathrm{obs}(\mathrm{T})} v s[\mathrm{CPC}]_{\mathrm{T}}$ profile $(c f$. Fig. 3) indicates that the rate decreases in a continuous fashion and it tends to level off at higher concentration of CPC. Bunton and Cerichelli [42] noted a similar observation 
in the oxidation of ferrocene by $\mathrm{Fe}^{\mathrm{III}}$ salts in the presence of cationic surfactant cetyltrimethyl ammonium bromide (CTAB). The present observation is also similar to those observed by Panigrahi and Sahu in the oxidation of acetophenone by Ce(IV), by Sarada and Reddi in the oxalic acid catalysed oxidation of aromatic azo-compounds by $\mathrm{Cr}(\mathrm{VI})$ in the presence of surfactant sodium dodecyl sulfate (SDS). In the uncatalysed path, the neutral $\mathrm{Cr}(\mathrm{VI})$ - substrate ester (A) formed (cf. Eqn.5) can be partitioned in the micellar pseudo-phase of the surfactant but the cationic surfactant repelling $\mathrm{H}^{+}$needed for the reaction (cf. Eqn. 6) inhibits the reaction. In the bpy- catalysed path, CPC restricts the positively charged $\mathrm{Cr}(\mathrm{VI})$-bpy complex $\left(\mathrm{C}_{1}\right)$, the active oxidant, in the aqueous phase and thus the accumulated neutral substrate in the micellar phase (Stern layer) cannot participate in the reaction. Therefore, in the bpy-catalysed path, the reaction is mainly restricted in the aqueous phase in which the concentration of the substrate is depleted due to its partitioning into the Stern layer of the micelle. Partitioning of the reactants between the aqueous and micellar phase is shown in Scheme 3 in which $D_{n}$ represents the micellised surfactants where ' $n$ ' is the aggregation number.

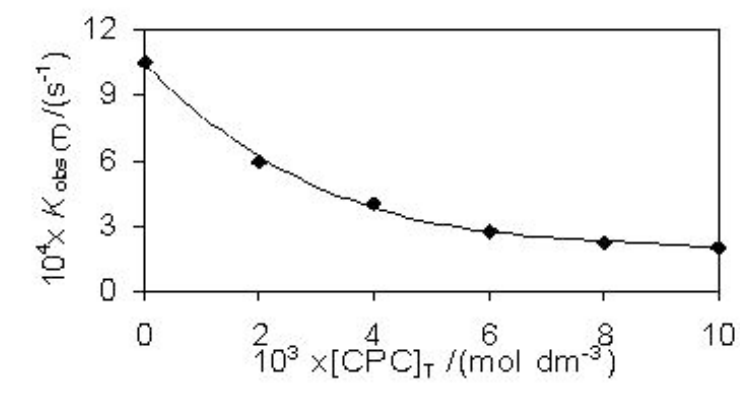

Fig. (3). Effect of $[\mathrm{CPC}]_{\mathrm{T}}$ on $k_{\mathrm{obs}(\mathrm{T})}$ for the $\mathrm{Cr}(\mathrm{VI})$ oxidation of $\mathrm{D}$ galactose in the presence of bpy in aqueous $\mathrm{H}_{2} \mathrm{SO}_{4}$ media, $[\mathrm{Cr}(\mathrm{VI})]_{\mathrm{T}}$ $=5 \times 10^{-4} \mathrm{~mol} \mathrm{dm}^{-3},\left[\mathrm{H}_{2} \mathrm{SO}_{4}\right]_{\mathrm{T}}=0.5 \mathrm{~mol} \mathrm{dm}$. . [D-galactose $]_{\mathrm{T}}=$ $150 \times 10^{-4} \mathrm{~mol} \mathrm{dm}^{-3},[\mathrm{bpy}]_{\mathrm{T}}=100 \times 10^{-4} \mathrm{~mol} \mathrm{dm}^{-3}, \mathrm{~T}=40^{\circ} \mathrm{C}$.

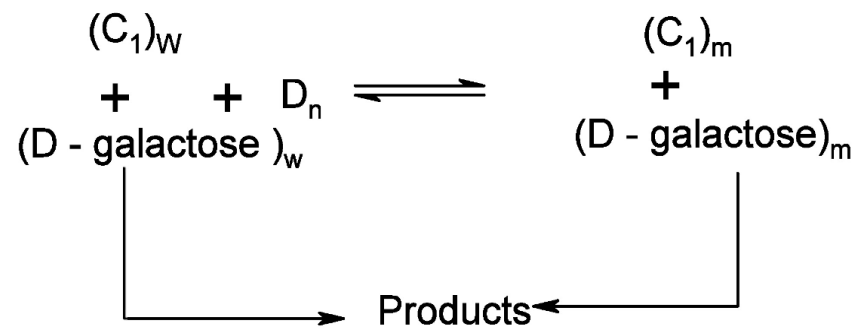

Scheme 3. Partitioning of the reactive species between the aqueous and micellar phases.

\section{EFFECT OF SDS}

Sodium dodecyl sulfate (SDS), a representative anionic surfactant accelerates both the uncatalysed and bpy-catalysed path. In the bpy-catalysed path, the rate accelerating effect arises due to the preferential partitioning of the positively charged $\mathrm{Cr}(\mathrm{VI})$-bpy complex $\left(\mathrm{C}_{1}\right)$ (by electrostatic attraction) and neutral substrate (probably by hydrophobic attraction) in the micellar inter phase. In the uncatalysed path, the neutral $\mathrm{Cr}(\mathrm{VI})$ - substrate ester (A) is the partitioned in the micellar inter phase (Stern layer) and the $\mathrm{H}^{+}$ions needed for the redox decomposition of the ester (A) (Eqn. 6 and 7) are also preferentially accumulated in the micellar inter phase due to electrostatic attraction. Thus SDS allows the reaction to proceed in both the aqueous and micellar inter phases. However the reaction is more favoured in the micellar pseudophase because of the enhanced concentration of the reactants in the micellar inter phase.

In the bpy-catalysed reaction, the plot of $k_{\mathrm{obs}(\mathrm{T})} v s$ [cf. $\mathrm{SDS}]_{\mathrm{T}}$ ( $c f$. Fig. 4) indicates that the rate increases in a continuous fashion up to the SDS concentration used. An increase in $[\mathrm{SDS}]_{\mathrm{T}}$ increases the micellar solubilisation of the reactants but at the same time an increase in $[\mathrm{SDS}]_{\mathrm{T}}$ increases the concentration of the micellar counter ions (i.e. $\mathrm{Na}^{+}$) which may displace $\mathrm{H}^{+}$and $\mathrm{OX}^{2+}$ ions $\left(\mathrm{C}_{1}\right)$ out of micellar surface.

$$
\begin{aligned}
2 \mathrm{Na}_{\mathrm{W}}^{+}+\mathrm{OX}_{\mathrm{M}}^{2+} \rightleftharpoons 2 \mathrm{Na}_{\mathrm{M}}^{+}+\mathrm{OX}_{\mathrm{W}}^{2+} \\
\mathrm{Na}_{\mathrm{W}}^{+}+\mathrm{H}_{\mathrm{M}}^{+} \rightleftharpoons \mathrm{Na}_{\mathrm{M}}^{+}+\mathrm{H}_{\mathrm{W}}^{+}
\end{aligned}
$$

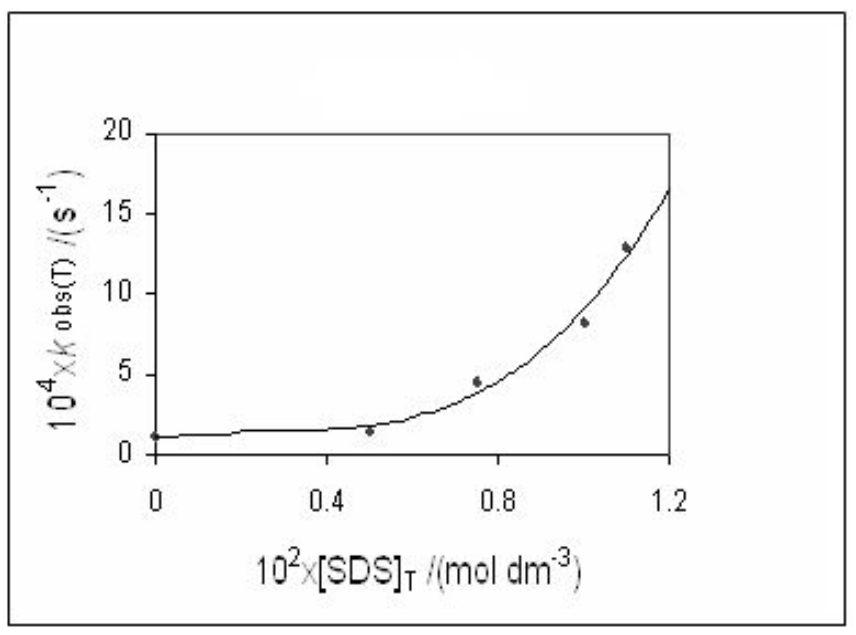

Fig. (4). Effect of $[\mathrm{SDS}]_{\mathrm{T}}$ on $k_{\mathrm{obs}(\mathrm{T})}$ for the $\mathrm{Cr}(\mathrm{VI})$ oxidation of Dgalactose in the presence of bpy in aqueous $\mathrm{H}_{2} \mathrm{SO}_{4}$ media, [Cr(VI) ]$_{\mathrm{T}}=5 \times 10^{-4} \mathrm{~mol} \mathrm{dm}^{-3},[\mathrm{bpy}]_{\mathrm{T}}=8 \times 10^{-3} \mathrm{~mol} \mathrm{dm}^{-3},\left[\mathrm{H}_{2} \mathrm{SO}_{4}\right]=0.25 \mathrm{~mol}$ $\mathrm{dm}^{-3},[\text { D-galactose }]_{\mathrm{T}}=6 \times 10^{-3} \mathrm{~mol} \mathrm{dm}^{-3}, \mathrm{~T}=35^{\circ} \mathrm{C}$.

The plot of $k_{\mathrm{obs}(\mathrm{T})}$ vs $[\mathrm{SDS}]_{\mathrm{T}}$ indicates that the solubilisation effect is greater than the counter ion effect for the bpy-catalysed path up to the used SDS concentration. Here it may be pointed out that the product galactonic acid is also partitioned between the micellar (both cationic and anionic) and aqueous phases. However, this partitioning does not have any effect on the rate process and reaction mechanism.

\section{CONCLUSIONS}

The Cr(VI)-bpy complex, a cationic species has been found to act as the active oxidant in the bpy-catalysed chromic acid oxidation of D-galactose to give the product Dgalactonic acid. This cationic species reacts with the substrate galactose to form a ternary complex which subsequently experiences a 2e-transfer redox decomposition in the rate determining step. The effects of both the cationic and anionic surfactants have been followed and the observed micellar effects are in agreement with the proposed reaction 
mechanism. The mechanistic paths of uncatalysed and bpycatalysed chromic acid oxidation of D-galactose have been compared

The organic product, D-galactonic acid was identified by paper chromatography. This was supported by comparing with the paper chromatogram of the authentic compound. The state of $\mathrm{Cr}$ (III)-species in the final solution has been detected by following the UV-visible spectra. In the uncatalysed reaction, the species is simply $\mathrm{Cr}$ (III)- species (pale blue, $\lambda_{\max }=415 \mathrm{~nm}$ and $580 \mathrm{~nm}$ ) while for the bpycatalysed path, the corresponding species is a $\mathrm{Cr}(\mathrm{III})$-bpy complex (pale violet colour, $\lambda_{\max }=542 \mathrm{~nm}$ ). This $\mathrm{Cr}$ (III)-bpy complex is not formed by the interaction of bpy with the $\mathrm{Cr}$ (III)-species produced after reduction of $\mathrm{Cr}$ (VI) because Cr(III) $\left(\mathrm{t}_{2 \mathrm{~g}}{ }^{3}\right)$ is kinetically very inert. From an independent experiment, it has been noted that under the comparable conditions, the spectrum of a mixture containing $\mathrm{Cr}(\mathrm{aq})^{3+}$ and bpy does not change within the reaction time (required for the present redox reaction initiated by $\mathrm{Cr}(\mathrm{VI})$ ). This is why, it is concluded that bpy does not ligate with the $\mathrm{Cr}$ (III) centre after its generation from $\mathrm{Cr}(\mathrm{VI})$. Existence of the $\mathrm{Cr}$ (III)-bpy complex in the final solution supports the formation of $\mathrm{Cr}(\mathrm{VI})$-bpy complex in the pre-equilibrium step because the $\mathrm{Cr}(\mathrm{VI})$ centre is kinetically labile. This Cr(VI)-bpy complex is finally reduced to $\mathrm{Cr}$ (III)-bpy complex.

\section{ACKNOWLEDGEMENTS}

Financial support from DST - FIST (New Delhi), UGCSAP (New Delhi) and Visva-Bharati University, (Santiniketan) is thankfully acknowledged.

\section{REFERENCES}

[1] Gonzalez, J. C.; Garcia, S.; Mamana, N.; Sala, L. F.; Sinorella, S. Evidence for the involment of $\mathrm{Cr}^{\mathrm{II}}$ and free radicals as intermediates in the reduction of $\mathrm{HCrO}_{4}^{-}$by saccharides, alcohols and hydroxyl acids. J. Inorg. Chem. Commun., 2006, 9, 437-440.

[2] Sebastian, E.; Gonzalez, J. C.; Garcia, S. I.; Signorella, S. R.; Sala, F. L. Kinetics and mechanism of oxidation of apple pectin by $\mathrm{Cr}^{\mathrm{VI}}$ in aqueous acid media. J. Phys. Org. Chem., 2008, 21, 1059-1067.

[3] Naik, P.N.; Chimatadar, S.T.; Nandibewoor. S.T. A kinetics and mechanistic study of the oxidation of tyrosine by chromium(VI) in aqueous perchloric acid medium. Trans. Met. Chem., 2008, 33, 405-410.

[4] Rajarajan, G.; Jayachandramani, N.; Manivarman, S.; Jayabharathi, J.; Thanikachalam, V. Kinetics and mechanism of oxidation of $N, a-$ diphenylnitrones by 4-(dimethylamino)pyridinium chlorochromate (DMAPCC) in aqueous DMF medium. Trans. Met. Chem., 2008, 33, 393-397.

[5] Ghammamy, S.; Baghy, M. R. Some aspects of tetramethylammonium fluorochromate (VI) oxidations and identification of the reduced chromium species. Trans. Met. Chem., 2007, 32, 456-460.

[6] Dwars, T.; Paetzold, E.; Oehme, G. Reactions in micellar systems. Angew. Chem. Int. Ed., 2005, 44, 7174-7199.

[7] Saha, B.; Das, M.; Mohanty, R. K.; Das, A. K. Micellar effect on the reaction of chromium(VI) oxidation of L-sorbose in the presence and absence of picolinic acid in aqueous acid media: a kinetic study. J. Chin. Chem. Soc., 2004, 51, 399-408.

[8] Saha, B.; Islam, M.; Das, A. K. Micellar effect on the reaction of chromium (VI) oxidation of lactic acid and malic acid in the presence and absence of picolinic acid in aqueous acid media. Inorg. React. Mech., 2005, 6, 141-149.

[9] Das, A. K. Micellar effect on the kinetics and mechanism of chromium(VI) oxidation of organic substrates. Coord. Chem. Rev., 2004, 248, 81-99.

[10] Hintze, R. F.; Rocek, J. Catalysis in oxidation reactions. 3. The oxalic acid catalyzed chromic acid oxidation of tris $(1,10-$ phenanthroline) iron(II). J. Am. Chem. Soc., 1977, 99, 132-137.
[11] Satyanarayana, T.; Anipindi, N. R.; Subbiah, V.; Pandit, M. W. The oxalic acid catalysed oxidation of bis(2,4,6-tripyridyl-1,3,5triazine)- iron(II) by chromium(VI) in acetate buffer. Trans. Met. Chem., 1993, 18, 93-95.

[12] Srinivasan, C.; Rajagopal, S.; Chellamani, A. Mechanism of picolinic- acid-catalysed chromium(VI) oxidation of alkyl aryl and diphenyl sulphides. A. J. Chem. Soc. Perkin. Trans., 1990, 2, 18391843

[13] Das, A. K.; Mondal, S.K.; Kar, D.; Das, M. Micellar Effect on the reaction of picolinic acid catalysed chromium(VI) oxidation of dimethylsulfoxide in aqueous acidic media: a kinetic study. Int. $J$. Chem. Kinet., 2001, 33, 173-181.

[14] Das, A. K.; Mondal, S. K.; Kar, D.; Das, M. micellar effect on the reaction of chromium(VI) oxidation of D-glucose in the presence and absence of picolinic acid in aqueous media: a kinetic study. Inorg. React. Mech., 2001, 3, 63-74.

[15] Das, A. K.; Mondal, S. K.; Kar, D.; Das, M. Kinetics and mechanism of picolinic acid promoted chromium(VI) oxidation of dimethylsulfoxide in the presence and absence of surfactants. $J$. Chem. Res. (S)., 1998, 574-575.

[16] Bayen, R.; Islam, M.; Saha, B.; Das, A. K. Oxidation of D-glucose in presence of $2,2^{\prime}$-bipyridine by chromium(VI) in aqueous micellar media: a kinetic study. Carbohydr. Res., 2005, 340, 2163-2170.

[17] Saha, B.; Islam, M.; Das, A. K. Kinetics and mechanism of 2,2'bipyridine catalysed chromium(VI) oxidation of dimethyl sulfoxide in the presence and absence of surfactants. J. Chem. Res. (S)., 2005, 471-474.

[18] Khan, Z.; Kabir-ud-Din. Kinetics and mechanism of ethylenediaminetetraacetic acid-, 2,2'-bipyridyl-, and 1,10phenanthroline - assisted chromium(VI) oxidation of 2-propanol. Trans. Met. Chem., 2002, 27, 832-839.

[19] Hasan, F.; Rocek. J. Three-electron oxidation. II. The chromium(VI) oxidation of oxalic acid. J. Am. Chem. Soc., 1972, 94, 3181 .

[20] Das, A. K. Kinetics and mechanism of the chromium(VI) oxidation of formic acid in the presence of picolinic acid and in the presence and absence of surfactants. Inorg. React. Mech., 1999, 1, 161-168.

[21] Rizzotto, M.; Frascaroli, M. I.; Signorella, S.; Sala, L. F. Oxidation of L-rhamnose and D-mannose by chromium(VI) in aqueous acetic acid. Polyhedron, 1996, 15, 1517-1523.

[22] Sala, L. F.; Signorella, S. R.; Rizzotto, M.; Frascaroli, M. I.; Gandolfo F. Oxidation of L-rhamnose and D-mannose by $\mathrm{Cr}(\mathrm{VI})$ in perchloric acid. A comparative study. Can. J. Chem., 1992, 70, 2046-2052.

[23] Sengupta, K. K.; Sengupta, S.; Basu, S. N. Kinetics and mechanism of oxidation of some aldoses by chromic acid in perchloric acid medium. Carbohydr. Res., 1979, 71, 75-84.

[24] Trevelyan, W.; Procter D.; Harrison, J. Detection of sugar on paper chromatograms. Nature, 1950, 166, 44471.

[25] Morrison, R. T.; Boyd, R. N. Organic Chemistry, 5th ed.; Prentice Hall of India Private Limited publishing Co: New Delhi-110001, 1989; p. 1286

[26] Daier, V.; Signorella, S.; Rizzotto, M.; Frascaroli, M. I.; Palopoli, C.; Brondino, C.; Salas-Peregrin, J. M.; Sala, L. F. Kinetics and mechanism of the reduction of $\mathrm{Cr}^{\mathrm{VI}}$ to $\mathrm{Cr}^{\mathrm{III}}$ by D-ribose and 2deoxy-D-ribose. Can. J. Chem., 1999, 77, 57-64.

[27] Lin, T. Y.; Zeng, H. W.; Chuo, C. M. Kinetics of 2,2'-bipyridylcatalyzed oxidation of isopropyl alcohol with chromic acid. $J$. Chin. Chem. Soc., 1995, 42, 43-49.

[28] Carrington, A.; Symons, M. C. R. Structure and reactivity of the oxyanions of transition metals. Chem. Rev., 1962, 5, 443-460.

[29] Sengupta, K. K.; Basu, S. N. Kinetics and mechanism of oxidation of oxidation of D-glucose and D-ribose by chromium(VI) and vanadium(V) in perchloric acid medium Carbohydr. Res., 1980, $80,223-232$

[30] Capon, B. Mechanism in carbohydrate chemistry. Chem. Rev., 1969, 69, 407-498.

[31] Rudram, M.; Shaw, D. F. The structure and conformation of some monosaccharides in solution. J. Chem. Soc., 1965, 52-57.

[32] Cantor, S. M.; Peniston, Q. P. The reduction of aldoses at the dropping mercury cathode: estimation of the aldehydo structure in aqueous solutions. J. Am. Chem. Soc., 1940, 62, 2113-2121.

[33] Bell, R. P. Acid-Base Catalysis. Clarendon Press: Oxford, 1941, p. 66 
[34] Bently, R. The relationship of oxidation rate and molecular conformation of sugar anomers J. Am. Chem. Soc., 1957, 79, 17201725 .

[35] Kar, D. Ph.D. Thesis, Visva-Bharati University, West Bengal, India, 2002.

[36] Sillen, L. G.; Mertell, A. E. Stability Constants of Metal - Ion Complexes, Special publication No. 25. The Chemical Society: London, 1971; Suppl. 1, p. 598.

[37] Watanabe, W.; Westheimer, F. H. The kinetics of the chromic acid oxidation of isopropyl alcohol: the induced oxidation of manganous ion. J. Chem. Phys., 1949, 17, 61-70.

[38] Perez-Bennito, J. F.; Arias, C.; Lamrhari, D. Evidence for the involvement of chromium(II) as an intermediate in the reduction of
chromium(VI) to chromium(III) by formaldehyde. J. Chem. Soc. Chem. Commun., 1992, 472-474.

[39] Perez-Bennito, J. F.; Arias, C. A kinetic study on the reactivity of chromium(1V). Can. J. Chem., 1993, 71, 649-655.

[40] Hasan, F.; Rocek. J. The chromic acid oxidation of oxalic acid: evidence of chromium(IV) oxidation. Tetrahedron, 1974, 30, 2124.

[41] Bilmer, F. W. Text Book of Polymer Sciences. Wiley: New York, 1984, p 85.

[42] Bunton, C. H.; Cerichelli, G. Micellar effects upon electron transfer from ferrocenes. Int. J. Chem. Kinet., 1980, 12, 519-533.

(C) Bayen and Das; Licensee Bentham Open.

This is an open access article licensed under the terms of the Creative Commons Attribution Non-Commercial License (http://creativecommons.org/licenses/by$\mathrm{nc} / 3.0 /$ ) which permits unrestricted, non-commercial use, distribution and reproduction in any medium, provided the work is properly cited. 